\title{
Genetic Analysis Studies in Potato (Solanum tuberosum L.) Genotypes for Tuber Yield and Yield Related Traits
}

\author{
Awoke Ali Zeleke ${ }^{1, *}$, Tiegist Dejene Abebe ${ }^{2}$, Baye Berihun Getahun ${ }^{3}$ \\ ${ }^{1}$ Ethiopian Institute of Agricultural Research, Kulumsa Agricultural Research Centre, Asella, Ethiopia \\ ${ }^{2}$ College of Agriculture and Environmental Science, Bahir Dar University, Bahir Dar, Ethiopia \\ ${ }^{3}$ College of Agriculture and Environmental Science, Woldia University, Woldia, Ethiopia
}

\section{Email address:}

awokeali2014@gmail.com (A. A. Zeleke), tiegistdejene@gmail.com (T. D. Abebe), baye.bgetahun@gmail.com (B. B. Getahun)

${ }^{*}$ Corresponding author

\section{To cite this article:}

Awoke Ali Zeleke, Tiegist Dejene Abebe, Baye Berihun Getahun. Genetic Analysis Studies in Potato (Solanum tuberosum L.) Genotypes for Tuber Yield and Yield Related Traits. Agriculture, Forestry and Fisheries. Vol. 10, No. 5, 2021, pp. 196-202. doi: $10.11648 /$ j.aff.20211005.15

Received: March 24, 2021; Accepted: October 19, 2021; Published: October 29, 2021

\begin{abstract}
Potato is a high potential food security crop in the world including Ethiopia. Genetic variability is the basis of all crop improvement programs. The study was conducted at Adet in 2018 with the objective of assessing the extent and pattern of genetic variability of potato genotypes for yield and yield related traits. A total of 36 potato genotypes were evaluated for 18 quantitative traits in simple lattice design with two replication. The analysis of variance revealed that highly significant $(\mathrm{p} \leq$ 0.001) difference among the tested potato genotypes for all quantitative traits except average stem number per hill. The phenotypic coefficient of variation was ranged from 4.56 to $56.01 \%$ (specific gravity and unmarketable tuber yield $t \mathrm{ha}^{-1}$ respectively) and the genotypic coefficient of variation was ranged between 2.32 to $40.66 \%$ (specific gravity and late blight severity percentage respectively). The broad sense heritability was ranged from 25.93 to $97.05 \%$ (specific gravity and late blight severity percentage respectively) and the genetic advance as percent of mean was ranged from 2.44 to $82.64 \%$ (specific gravity and late blight severity percentage respectively). Days to attain $50 \%$ emergence, leaf area index, number of marketable tubers and total tubers per plant, marketable and total tuber yield $\mathrm{t} \mathrm{ha}^{-1}$ and late blight severity percentage had high heritability with high genetic advance as percent of mean. Most of the traits had high phenotypic coefficient of variation and genotypic coefficient of variation; and coupled high heritability with high genetic advance as percent of mean. Traits having high heritability and high genetic advance as percent of means was effective for simple selection.
\end{abstract}

Keywords: Coefficient of Variation, Genotype, Heritability, Late Blight, Phenotype, Potato

\section{Introduction}

The crop Potato (Solanum tuberosum L.) is one of the most important food crops worldwide including Ethiopia. It ranks third after rice and wheat in terms of human consumption [1]. According to FAO [2] report the total world potato production was $370,436,581$ metric tons. China was by far the largest potato producer, accounting for $24.8 \%$ of world production [2]. In Ethiopia, during 2019/20 growing season more than 1 million small holders are engaged in potato production. The total area allocated for potato has reached $70,362.22$ ha, total production of $924,728.361$ tons produced [3]. Ethiopia ranked in $11^{\text {th }}$ in Africa and it covers $0.25 \%$ of the total world potato production [2]. Currently, Potato is a high potential food security crop in Ethiopia due to its high yield potential, nutritional quality, short growing period and wider adaptability [4]. On the other hand, the productivity of this crop in the country is very low (13.14 $\mathrm{t} \mathrm{ha}^{-1)}$ as compared to the world's average yield of 20.36 tons $\mathrm{ha}^{-1}[2,3]$. The lower yield is attributed to many biotic and abiotic factors, such as poor agronomic practices, lack of high-quality and improved planting material, high cost of improved seed tubers, disease and pest problems $[5,6]$.

The use of local tuber seed and varieties with low genetic variability are the major constraints of low yield in potato. Breeders should take the challenge to provide food at cheaper rate to the millions of hungry people in developing countries 
by increasing the production of potato per unit area and per unit time. To initiate any breeding program to this direction, presence of enough genetic variability in the population for yield and yield related traits should be considered as pre requisite element. Moreover, application of perfect breeding method is dependent on estimation of genetic gain of the characters for successful selection as to develop desirable traits suggested by Johnson et al. [7].

Plant breeding or crop improvement depends upon the magnitude of genetic variability and extent to which the desirable characters are heritable. Genetic variability is the basis of all crop improvement programs. Sufficient genetic variability, if present, can be exploited for developing superior cultivar or varieties. The total variability can be partitioned into heritable and non-heritable components with the help of genetic parameters like genotypic and phenotypic coefficients of variation, heritability and genetic advance. Parameters of genotypic and phenotypic coefficients of variation (GCV and PCV) are useful in detecting the amount of variability present in the available genotypes. Heritability and genetic advance help in determining the influence of environment expression of the characters and the extent to which improvement is possible after selection [8]. High heritability alone is not enough to make efficient selection in segregating generation, unless the information is accompanied for substantial amount of genetic advance [7]. Rahman [9] also reported that knowledge on the nature of variability and association of yield with its components is of great impotence for identification of superior parents in any breeding program.

In Ethiopia, potato breeding method depends on conventional breeding method such as introduction of potato germplams from International Potato Center (CIP) every year. Thus indicated that introduced potato genotypes needs to be characterized and evaluated, because quantitative traits are strongly influenced by environmental factors. Knowing the nature of genetic variability and diversity of genotypes is essential to use as a base material for further breeding program and to meet the diversified goals of plant breeding such as for increasing tuber yield, wider adaptation, desirable quality, pest and disease resistance. Therefore, the objective of the present study is to assess the extent and pattern of genetic variability of potato genotypes for agronomic, yield and tuber quality traits.

\section{Materials and Methods}

\subsection{Description of the Study Area}

The experiment was conducted at Adet Agricultural Research Center's experimental station in Northwestern Ethiopia. It is nearly $450 \mathrm{~km}$ away from Addis Ababa and 42 $\mathrm{km}$ from the Capital City of Amhara Regional State Bahir Dar. Geographically, it is located at $11^{\circ} 16^{\prime} \mathrm{N}$ latitude and $37^{\circ} 29^{\prime} \mathrm{E}$ longitude at an altitude of 2240 meter above sea level. The mean annual rain fall is $869 \mathrm{~mm}$ and the mean annual temperature is $18.56^{\circ} \mathrm{C}$ [10]. The soil type of the study area is Nitosol soil.

Table 1. List of potato genotypes and accession code.

\begin{tabular}{|c|c|c|c|c|c|c|c|}
\hline No. & Accession code & No. & Accession code & No. & Accession code & No. & Accession code \\
\hline 1 & CIP-308517.501 & 10 & CIP-308530.501 & 19 & CIP-308511.507 & 28 & CIP-308499.501 \\
\hline 2 & CIP-308527.501 & 11 & CIP-308525.01 & 20 & CIP-308499.001 & 29 & CIP-308530.002 \\
\hline 3 & CIP-308510.03 & 12 & CIP-308500.01 & 21 & CIP-308482.506 & 30 & CIP-308523.500 \\
\hline 4 & CIP-308985.01 & 13 & CIP-308522.503 & 22 & CIP-308522.502 & 31 & CIP-308482.504 \\
\hline 5 & CIP-308526.502 & 14 & CIP-308527.502 & 23 & CIP-308518.001 & 32 & CIP-308516.501 \\
\hline 6 & CIP-3038522.504 & 15 & CIP-395077.120 & 24 & CIP-308487.500 & 33 & CIP-308482.505 \\
\hline 7 & CIP-308517.500 & 16 & CIP-308511.508 & 25 & CIP-308516.500 & 34 & Gudanie (CIP-386423.13) \\
\hline 8 & CIP-308526.501 & 17 & CIP-308522.501 & 26 & CIP-308532.500 & 35 & Belete (CIP-393371.58) \\
\hline 9 & CIP-308499.502 & 18 & CIP-308485.002 & 27 & CIP-308522.500 & 36 & Dagim (CIP-396004.337) \\
\hline
\end{tabular}

\subsection{Experimental Design, Treatments and Procedures}

A total of 36 potato genotypes consisting of 33 advanced genotypes were introduced from International Potato Center (CIP) and three recently nationally released potato varieties as standard checks were used (Table 1). All of the 36 genotypes were planted at Adet Agricultural Research Center on station during the main rainy cropping season in 2018. The genotypes arranged in simple lattice design with two replications and each gross plot were $3 \mathrm{~m}$ $\mathrm{x} 3 \mathrm{~m}=9 \mathrm{~m}^{2}$ consisting of four rows, which accommodated 10 plants per row and thus 40 plants per plot. The net plot size is $1.5 \mathrm{~m} \times 2.4 \mathrm{~m}=3.6 \mathrm{~m}^{2}$. The spacing between rows and plants were $0.75 \mathrm{~m}$ and $0.30 \mathrm{~m}$, respectively. The spacing between plots and adjacent replications were $1 \mathrm{~m}$ and $1.5 \mathrm{~m}$, respectively. The experimental field was cultivated to a depth of $25-30 \mathrm{~cm}$ by a tractor and ridges were made manually after leveling. Fertilizer application was made as per the specific recommendation for the location, in which NPS as a source of phosphorus was applied at a rate of $180 \mathrm{~kg} / \mathrm{ha}$ and Urea as a source of nitrogen was applied at rate of 117 $\mathrm{kg} / \mathrm{ha}$. NPS was applied once during planting in the rows, while urea was applied in split application half at emergence and half at $50 \%$ flowering as a side dress application [11]. All other agronomic practices such as weeding, cultivation and spraying Redomil chemical were kept uniform for all treatments in each plot. The two middle rows were used for data collection.

All tested potato genotypes was introduced from CIP (International Potato Center) \& the released varieties were from Adet Agricultural Research Center. 


\subsection{Data Collection}

\subsubsection{Phonological, Growth, Tuber Yield and Yield Related Traits Was Collected as Follows}

Days to $50 \%$ emergence: - the numbers of days from planting to the emergence of $50 \%$ of plants in each plot was recorded.

Days to $50 \%$ flowering: - was recorded as actual number of days taken from emergence to the days at which $50 \%$ of the plants in each plot produced flowers.

Days to maturity: - was recorded by counting days from emergence to days on which more than $90 \%$ of the plant in each plot get yellow.

Plant height in cm: - The height of five plants in each plot was measured in centimeter from the ground surface to the tip of the main stem and averaged to get the mean plant height.

Number of stem per plant: - It was recorded as the average stem count of five hills or plant per plot at 50\% flowering. Only stems that were emerged independently above the soil as single stems were considered as main stems.

Leaf area index (LAI):- To determine leaf area index, five plants (hills) were used from each plot. Individual leaf area of the potato plants was estimated from individual leaf length by using the formula developed by Firman et al. [12] and leaf area index were determined by dividing the total leaf area of a plant by the ground area covered by a plant.

Log 10 (leaf area in $\mathrm{cm} 2)=2.06 \times \log 10$ (leaf length in $\mathrm{cm})-0.458$.

Number of marketable tubers per plant: - Number of tubers harvested from five plants (hills) which counted as marketable after sorting tubers which have greater or equal to $20 \mathrm{~g}$ weight, free from disease and insect attack. The average number of marketable tubers were counted and registered.

Number of unmarketable tubers per plant: - The tubers that are sorted as diseased, insect attacked and small-sized $(<20$ g) from five plants as indicated in the above were recorded as unmarketable tuber number. The average number of unmarketable tubers were counted and registered.

Total tuber number per hill: - the total number of tubers produced per plant was recorded or it was recorded by the sum of both marketable and unmarketable tubers number per plant.

Average tuber weight $\left(\mathrm{g}\right.$ tuber $\left.^{-1}\right)$ :- It was determined by dividing the total fresh tuber weight to the respective total tubers number which was harvested from five plants (hills).

Marketable tuber yield ( $\left.\mathrm{t} \mathrm{ha}{ }^{-1}\right)$ :- The total tuber weight which were free from diseases, insect pests, and greater than or equal to $20 \mathrm{~g}$ in weight determined from the net plot area and were converted to tons per hectare.

Unmarketable tuber yield ( $\mathrm{t} \mathrm{ha-}^{1}$ ):- was determined by weighting tubers that were sorted out as diseased, insect attack and small-sized $(<20 \mathrm{~g})$ from the net plot area and converted to tons per hectare.

Total tuber yield $\left(\mathrm{t} \mathrm{ha}^{-1}\right)$ :- This was determined as the sum of the weights of marketable and unmarketable tubers from the net plot area and converted to tons per hectare.

\subsubsection{Tuber Quality Attributes Was Calculated as Follows}

Tuber dry matter content (TDMC) (\%):- Five fresh tubers were randomly taken from each plot, washed, weighed and sliced at harvest, dried for seven days under sun and finally in oven at $75^{\circ} \mathrm{C}$ for 72 hours until a constant weight attained and dry matter percent calculated according to William et al. [13] formula.

$$
\text { Dry matter }=\frac{\text { weight of sample after drying }(\mathrm{g})}{\text { initial fresh weight of sample }(\mathrm{g})} * 100
$$

Specific gravity of tubers (SG):- was determined by the weight in air and in water method. Five $\mathrm{kg}$ tuber of all shapes and sizes were randomly taken from each plot. The tubers were washed with water. Then after the sample were first weighed in air and then re-weighed suspended in water. Specific gravity was calculated according to Kleinkopf et al. [14] formula.

$$
\text { Specific gravity }=\frac{\text { Weight in air }}{\text { Weight in air-Weight in water }}
$$

Starch (\%): The percentage of starch was calculated from the specific gravity, a formula developed by Talburt et al. [15].

Starch $(\%)=17.546+199.07 \times($ SG-1.0988). Specific gravity (SG) was determined as indicated above by the weight in air and weight in water method.

Total soluble solids ( ${ }^{\circ}$ Brix):- The Brix of the raw potato samples was determined using a method as described by Pardo et al. [16] using hand refractometer. The Brix was measured in the juice obtained after washing, crushing and extracting juice of the tuber samples.

\subsubsection{Disease Data}

Assessment of severity of late blight under field conditions in percent was recorded on a plot basis taking into account the number of plants developing disease symptoms in a leaf and/or many leaves and plants free from disease following the procedures of Heinfnings [17].

\subsection{Statistical Data Analysis}

\subsubsection{Analysis of Variance}

The collected data were subjected to analysis of variance (ANOVA) for Simple Lattice by SAS (Statistical Analysis Software) version (9.0). Duncan Multiple Range Test (DMRT) was used to compare means at $5 \%$ and $1 \%$ level of significance.

\subsubsection{Phenotypic and Genotypic Variances}

The phenotypic and genotypic variability of each quantitative trait was estimated as genotypic and phenotypic variance components and coefficient of variation. The phenotypic and genotypic variances were estimated according to the method suggested by Singh et al. [18] as follows:

$$
\text { Genotypic variance }\left(\sigma^{2} g\right)=\frac{\text { Msg-Mse }}{r}
$$

Where: $\sigma^{2} \mathrm{~g}=$ genotypic variance, $\mathrm{MSg}=$ mean square due to genotype, $\mathrm{MSe}=$ environmental variance (error mean 
square) and $r=$ number of replications.

$$
\text { Phenotypic variance }\left(\sigma^{2} p\right)=\sigma^{2} g+\sigma^{2} \text { e }
$$

Where: $\sigma^{2} \mathrm{p}=$ phenotypic variance, $\sigma^{2} \mathrm{~g}=$ genotypic variance, $\sigma^{2} \mathrm{e}=$ environmental variance.

Environmental variance $\left(\sigma^{2} \mathrm{e}\right)=\mathrm{MSe}$ where: $\mathrm{MSe}=$ error mean square.

Coefficient of variation at phenotypic, genotypic and environmental levels was estimated by using the formula, adopted by Burton et al. [19] as follows:

$$
\begin{aligned}
& \text { Genotypic Coefficient of Variation }(\mathrm{GCV})=\frac{(\sqrt{\sigma 2 g)}}{\overline{\mathrm{x}}} * 100 \\
& \text { Phenotypic Coefficient of Variation }(\mathrm{PCV})=\frac{(\sqrt{\sigma 2 p)}}{\overline{\mathrm{x}}} * 100
\end{aligned}
$$

Where: $P C V=$ Phenotypic coefficient of variation, $G C V=$ Genotypic coefficient of variation, $\overline{\mathrm{x}}=$ population mean of the character being evaluated. PCV and GCV values were categorized as low (0-10\%), moderate (10-20\%), and high $(>20 \%)$ as suggested by Sivasubramanian et al. [20].

\subsubsection{Broad Sense Heritability $\left(\mathrm{H}^{2} b\right)$}

Broad sense heritability was estimated based on the formula given by Allard and Falconer et al. [21, 22] as follows:

$$
\text { Heritability in broad sense } \mathrm{H}^{2} \mathrm{~b}=\frac{\sigma 2 \mathrm{~g}}{\sigma 2 \mathrm{p}} * 100
$$

Where: $H^{2} b=$ Heritability in broad sense, $\sigma^{2} p=$ phenotypic variance, $\sigma^{2} \mathrm{~g}=$ genotypic variance. According to Singh [23] heritability values regarded as low (0-40\%), medium (40$59 \%)$ moderately high $(60-79 \%)$ and very high $(80 \%$ and above).

\subsubsection{Estimation of Genetic Advance and Genetic Advance as Percent of Mean}

Genetic advance and genetic advance as percent of means were estimated as described by Allard [21] and Johnson et al. [7] as follows:

$$
\text { Genetic Advance }(\mathrm{GA})=\mathrm{K} \sigma \mathrm{p} \mathrm{H}_{\mathrm{b}}^{2}
$$

Where: $\mathrm{K}=$ the standardized selection differential at $5 \%$ (2.063), $\sigma \mathrm{p}=$ phenotypic standard deviation and, $\mathrm{H}_{\mathrm{b}}^{2}=$ heritability in broad sense

$$
\text { Genetic advance as percent of mean }(\mathrm{GAM})=\frac{G A}{\overline{\mathrm{x}}} * 100
$$

Where: $\mathrm{GA}=$ genetic advance, and $\overline{\mathrm{x}}=$ mean of population.

The GA as percent of mean was categorized as low (0$10 \%)$, moderate $(10-20 \%)$ and high $(>20 \%)$ as suggested by Johnson et al. [7].

\section{Results and Discussions}

\subsection{Analysis of Variance}

The result of Analysis of variance showed that there is highly significant $(\mathrm{p} \leq 0.001)$ difference among the tested potato genotypes for all traits except average stem number per hill/plant (Table 2). The findings on variance for tuber yield and its components indicates the existence of substantial amount of variability for most of the traits in experimental material studied. This provides an opportunity for a breeder to select best genotypes for their better tuber yield and other yield related traits. Many authors also reported the existence of significant variation among potato genotypes for different traits. Addisu Fekadu [24] reported that, highly significant difference among potato genotypes with respect to days to emergence, days to flowering, days to maturity, plant height, number of stem per plant, tuber number per plant and tuber yield (Kg) per plant. Similarly, highly significant difference for plant height, leaf area index, average tuber number per plant, average tuber weight (g/tuber), dry matter content (\%) and total tuber yield (t/ha) was reported by Rahman et al. [9, 25, 26].

Table 2. Analysis of variance for 18 traits at Adet Agricultural Research center in 2018 under rainy cropping season in lattice

\begin{tabular}{lllllll}
\hline Traits & Mean & Rep (1) & Genotype (35) & Error (35) & CV & $\mathbf{R}^{2}$ \\
\hline DE & 15.74 & 0.68 & $13.56^{* *}$ & 0.42 & 4.12 & 0.98 \\
DF & 48.13 & 3.13 & $11.48^{* *}$ & 1.43 & 2.48 & 0.93 \\
DM & 93.46 & 23.4 & $48.74 * *$ & 1.89 & 1.47 & 0.98 \\
SN & 5.12 & 3.92 & $2.3 n s$ & 1.66 & 25.15 & 0.74 \\
PH & 66.84 & 83.2 & $131 * *$ & 2.24 & 7.3 & 0.85 \\
LAI & 3.76 & 2.68 & $0.97 * *$ & 0.14 & 10.12 & 0.88 \\
MTNPH & 8.70 & 11.14 & $16.98^{* *}$ & 2.66 & 18.84 & 0.87 \\
UMTNPH & 2.90 & 0.80 & $2.2 *$ & 1.05 & 35.78 & 0.68 \\
TTNPH & 11.6 & 17.91 & $13.81 * *$ & 2.24 & 13 & 0.91 \\
ATW & 78.13 & 926.08 & $618.4 * *$ & 179.26 & 17.14 & 0.78 \\
MTY & 29.28 & 0.13 & $195.1 * *$ & 13.02 & 12.32 & 0.94 \\
UMTY & 3.08 & 0.36 & $4.36 * *$ & 1.63 & 41.2 & 0.73 \\
TTY & 32.36 & 0.05 & $206.7 * *$ & 12.30 & 10.81 & 0.94 \\
DMC & 23.03 & 2.12 & $14.89 *$ & 6.98 & 11.47 & 0.68 \\
SG & 1.14 & 0.0058 & $0.0034 *$ & 0.00185 & 3.77 & 0.66 \\
STA & 28.88 & 134.4 & $130.3 * *$ & 38.68 & 21.53 & 0.78 \\
TSS & 3.91 & 6.69 & $0.84 * *$ & 0.30 & 13.97 & 0.77 \\
LB & 59.58 & 50.0 & $1191.8 * *$ & 17.86 & 7.09 & 0.98 \\
\hline
\end{tabular}

Note: DE- Days to attain 50\% emergence, DF- days to attain 50\% flowering, DM- days to maturity, $\mathrm{PH}$ - plant height in $\mathrm{cm}$, SN-stem number per hill, LAI- leaf area index $\left(\mathrm{cm}^{-3}\right)$, MTNPH- marketable tuber number per hill/ plant, UMTNPH- un marketable tuber number per hill/plant, TTNPH- total tuber number per hill/plant, ATW-average tuber weight (g/tuber), MTYmarketable tuber yield ( $\mathrm{t} / \mathrm{ha})$, UMTY-un marketable tuber yield $(\mathrm{t} / \mathrm{ha})$, TTYtotal tuber yield (t/ha), DMC- dry matter content (\%), SG-specific gravity, STA- starch percentage $(\mathrm{g} / 100 \mathrm{~g})$, TSS- total soluble solid $\left({ }^{0}\right.$ brix $)$, LB-late blight severity percentage $(\%), \mathrm{CV}$ - coefficient of variation, $\mathrm{R}^{2}$ - coefficient of determination.

\subsection{Estimates of Variance Components}

The variability components (genotypic and phenotypic variance and coefficient of variations, heritability in broad sense and genetic advance as percent of mean) were estimated for seventeen traits and results are presented below in Table 3. However, the results excluded the one trait (stem number per hill/ plant) because of absence of significant difference at both $1 \%$ and $5 \%$ level of significant. 


\subsubsection{Phenotypic and Genotypic Coefficient of Variation}

The result of analysis of phenotypic coefficient of variation $(\mathrm{PCV})$ was relatively greater than the genotypic coefficient of variation (GCV) for all traits. It is due to presence of substantial influence of environmental factors besides the genetic variation for expression of these traits. The Phenotypic coefficient of variation (PCV) and genotypic coefficient of variation (GCV) values can be categorized as low $(<10 \%)$, moderate $(10-20 \%)$, and high $(>20 \%)$ by Sivasubramanian, S. et al. [20]. Based on these categories most of the traits such as marketable tuber number per hill (36.19 and 30.90\%), un marketable tuber number per hill (44.57 and $26.51 \%$ ), total tuber number per hill (24.59 and $20.87 \%$ ), marketable tuber yield $\mathrm{t} \mathrm{ha}^{-1}$ (34.84 and 32.59\%), un marketable tuber yield $\mathrm{t} \mathrm{ha}^{-1}$ (56.01 and 37.81\%), total tuber yield $\mathrm{t} \mathrm{ha}^{-1}(32.26$ and $30.40 \%)$, starch content percentage (31.83 and $23.44 \%$ ) and late blight severity percentage (41.28 and 40.66\%) had high PCV and GCV $(>20 \%)$, respectively. However, days to attain $50 \%$ flowering (5.28 and $4.66 \%$ ), days to maturity (5.38 and 5.18\%) and specific gravity (4.56 and 2.32\%) showed low PCV and GCV
$(<10 \%)$ respectively. Moderate PCV and GCV (10-20\%) was observed in days to attain $50 \%$ emergence (16.80 to 16.28 ), plant height in $\mathrm{cm}(13.16$ to $10.96 \%)$, leaf area index $(19.81$ to $17.13 \%$ ) and total soluble solid (19.26 to 13.26$)$. The highest magnitude of PCV and GCV was observed for unmarketable tuber yield per hectare (56.01 and 37.81\%) while the lowest PCV and GCV was observed in specific gravity (4.56 and 2.32\%) respectively. Average tuber weight (g/tuber) had high PCV $(25.56 \%)$ and moderate GCV (18.97\%). Moderate PCV (14.6\%) and low GVC (8.64\%) was observed in dry matter content percentage (Table 3 ). In agreement with this result, high PCV and GCV for tuber yield per plant, hectare, number of tuber per plant has been reported by Rahman et al. [9, 27, 28].

Similarly, Getachew Asefa et al. [25] also reported low PCV and GCV for days to maturity (7.6 and 7.2\%) and high PVC and GCV for marketable tuber number per hill (53.3 and $44.8 \%$ ), marketable yield $\mathrm{t} / \mathrm{ha}(51.2$ and $47.2 \%)$ and total tuber yield $\mathrm{t} / \mathrm{ha}$ (56.2 and 51.9\%). Higher PCV and GCV value (45.67 and $43.57 \%$ respectively) for late blight severity percentage was reported by [29].

Table 3. Estimate of variability components for 17 traits in 36 potato genotypes evaluated at Adet Agricultural Research Center in 2018 cropping season.

\begin{tabular}{|c|c|c|c|c|c|c|c|c|}
\hline Traits & $\sigma^{2} g$ & $\overline{\sigma^{2} p}$ & $\sigma^{2} \mathrm{e}$ & PCV (\%) & GCV (\%) & $H^{2} \mathbf{b}(\%)$ & $\overline{\text { GA }}$ & GAM (\%) \\
\hline $\mathrm{DE}$ & 6.57 & 6.99 & 0.42 & 16.80 & 16.28 & 93.99 & 5.13 & 32.57 \\
\hline DF & 5.03 & 6.46 & 1.43 & 5.28 & 4.66 & 77.85 & 4.08 & 8.48 \\
\hline DM & 23.43 & 25.31 & 1.88 & 5.38 & 5.18 & 92.57 & 9.61 & 10.28 \\
\hline PH & 53.66 & 77.33 & 23.67 & 13.16 & 10.96 & 69.39 & 12.59 & 18.83 \\
\hline LAI & 0.42 & 0.56 & 0.14 & 19.81 & 17.13 & 74.77 & 1.15 & 30.56 \\
\hline MTN & 7.16 & 9.82 & 2.66 & 36.19 & 30.90 & 72.91 & 4.71 & 54.43 \\
\hline UMTN & 0.58 & 1.63 & 1.05 & 44.57 & 26.51 & 35.38 & 0.93 & 32.54 \\
\hline ATW & 219.57 & 398.83 & 179.26 & 25.56 & 18.97 & 55.05 & 22.68 & 29.03 \\
\hline MTY & 91.04 & 104.06 & 13.02 & 34.84 & 32.59 & 87.49 & 18.41 & 62.88 \\
\hline UTY & 1.37 & 3.00 & 1.63 & 56.01 & 37.81 & 45.58 & 1.63 & 52.66 \\
\hline TTY & 97.18 & 109.48 & 12.30 & 32.26 & 30.40 & 88.76 & 19.16 & 59.08 \\
\hline DMC & 3.96 & 10.94 & 6.98 & 14.36 & 8.64 & 36.17 & 2.47 & 10.71 \\
\hline SG & 0.001 & 0.003 & 0.002 & 4.56 & 2.32 & 25.93 & 0.03 & 2.44 \\
\hline STA & 45.83 & 84.51 & 38.68 & 31.83 & 23.44 & 54.23 & 10.28 & 35.61 \\
\hline LB & 586.96 & 604.82 & 17.86 & 41.28 & 40.66 & 97.05 & 49.24 & 82.64 \\
\hline
\end{tabular}

Note: DE- Days to attain 50\% emergence, DF- days to attain 50\% flowering, DM- days to maturity, PH -plant height in cm, SN-stem number per hill, LAIleaf area index $\left(\mathrm{cm}^{-3}\right)$, MTNPH- marketable tuber number per hill/ plant, UMTNPH- un marketable tuber number per hill/plant, TTNPH- total tuber number per hill/plant, ATW-average tuber weight (g/tuber), MTY-marketable tuber yield ( $\mathrm{t} / \mathrm{ha})$, UMTY-un marketable tuber yield ( $\mathrm{t} / \mathrm{ha}$ ), TTY- total tuber yield ( $\mathrm{t} /$ ha), DMC- dry matter content (\%), SG-specific gravity, STA- starch percentage (g/100g), TSS- total soluble solid $\left({ }^{0}\right.$ brix $)$, LB-late blight severity percentage $(\%)$, $\sigma^{2} \mathrm{~g}$-genotypic variance, $\sigma^{2} \mathrm{p}$-phenotypic variance, $\sigma^{2} \mathrm{e}$ - environmental variance, GCV-genotypic coefficient of variation in percent, PCV-phenotypic coefficient of variation in percent, $\mathrm{H}^{2}{ }_{\mathrm{b}}$-heritability in broad sense, GA -expected genetic advance at $5 \%$ selection intensity, GAM-genetic advance as percent mean.

\subsubsection{Estimate of Broad Sense Heritability and Genetic Advance}

The estimated broad sense heritability and genetic advance for 17 quantitative traits was presented in Table 3. The minimum and maximum heritability and genetic advance value ranged from 25.93 to 97.05 and 0.03 to 49.24 for late blight severity percentage and specific gravity, respectively. The heritability was categorized as low $(0-40 \%)$, medium $(40-59 \%)$, moderately high $(60-79 \%)$ and very high (> $80 \%)$ as suggested by [23]. Based on these categories traits such as days to attain $50 \%$ emergence, days to maturity, marketable tuber yield $\mathrm{t} \mathrm{ha}^{-1}$, total tuber yield $\mathrm{t} \mathrm{ha}^{-1}$ and late blight severity percentage showed very high heritability $(>80)$. The highest heritability was recorded $(97.05 \%)$ for late blight severity percentage followed by days to attain $50 \%$ emergence (93.96\%) and days to maturity (92.57\%) (Table 3) In accordance with this result, high heritability for marketable tuber yield, total tuber yield has been reported by Rahman et al. [9, 27, 28, 30]. Similarly, higher heritability for late blight severity percentage $(91.02 \%)$ was reported by Mohammed W. [29].

The genetic advance as percent mean (GAM) was 
categorized as low $(0-10 \%)$, moderate $(10-20 \%)$ and high $(>20 \%)$ as suggested by Johnson et al. [7]. Accordingly, most of the traits showed high GAM $(>20 \%)$. However, days to maturity $(10.28 \%)$ and dry matter content $(10.71 \%)$, total soluble solid (18.82\%) and plant height (18.83) had moderate GA (10-20\%). High genetic advance was obtained from late blight percentage $(82.64 \%)$ and low genetic advance was obtained in specific gravity $(2.44 \%)$ followed by days to attain 50\% flowering (8.48\%) (Table 3$)$. In agreement with this result, the highest GAM was recorded for marketable tuber yield and total tuber yield has been reported by Rahman et al. $[9,28]$. The higher genetic advance as percent of mean for late blight intensity and severity percentage (96.31 and 85.63 respectively) was reported by Mohammed [29]. Medium GAM for plant height, dry matter content percentage was reported by Rahman [9]. Most of the traits coupled medium to very high heritability with high genetic advance except specific gravity and dry matter content percentage coupled with low heritability and low to medium genetic advance respectively (Table 3 ). Traits with high heritability couple with high GAM indicated additive gene action for the expression these traits and effective for simple selection while traits with low heritability couple with low GAM indicated non-additive gene action for the expression of these traits.

According to Panigrahi et al. [30] report high heritability coupled with high genetic advance in total tuber yield and marketable tuber yield was found indicating the influence of additive gene effect on these characters. High heritability coupled with high genetic advance for marketable tuber yield and total tuber yield was reported by Rahman et al. [9, 27, $28,30]$. Similarly, high heritability coupled with high GAM for leaf area index, number of tuber per plant was reported by Rahman et al. [9, 27].

\section{Conclusions}

The tested potato genotypes in the current study area showed statistically high significant difference at $(\mathrm{P} \leq 0.001)$ level of significance revealing presence of substantial amount of genetic variability. It confirms a positive response for the effectiveness of selection based on the traits with high and medium PCV and GCV values for trait of interest improvement. Most of the traits had high PCV and GCV; and coupled high heritability with high GAM. Traits with high heritability coupled with high genetic advance as percent of mean is also important for simple selection.

\section{Acknowledgements}

The first author acknowledges Adet Agricultural Research Center for giving the tested potato genotypes and supported in the field from planting to harvesting period. The authors also would like to express their special gratitude and warm appreciation to Ethiopian Institute of Agricultural Research (EIAR) for fully financing the study.

\section{References}

[1] FAOSTAT. 2015. Data base of agricultural production [online]. Available at http://faostat3.fao.org/home/E (updated 31 September 2015; accessed 11 October 2015). Food and Agriculture Organization, Rome, Italy.

[2] FAOSTAT. Retrieved 01 May 2019. Countries - Select All; Regions - World + (Total); Elements - Production Quantity; Items - Potatoes; Years - 2017.

[3] CSA. 2019/20. Agricultural Sample Survey Report on Area and Production (Private Peasant Holdings Meher Season. Central Statistical Agency of Ethiopia, Statistical Bulletin. Addis Ababa, Ethiopia.

[4] Tewodros, A., Paul, C. Struik and Adane, H. 2014. Characterization of seed potato (Solanum tuberosum L.) Storage, pre-planting treatment and marketing systems in Ethiopia: The case of West-Arsi Zone. African journal of agricultural research, 9 (15): pp. 1218-1226.

[5] Gebremedhin Woldegiorgis, Endale Gebre and Berga Lemaga. 2008. Potato variety development. Pp. 15-32. In: Gebremedhin Woldegiorgis, Endale Gebre and Berga Lemaga (eds.), Root and Tuber Crops: The Untapped Resources. Ethiopian Institute of Agricultural Research, Ethiopia. Addis Ababa, Ethiopia.

[6] Tesfaye Abebe and Yigzaw, D. 2008. Review of crop improvement research achievements and future focus in parts of Western Amhara Region: The case of Adet. Tesfaye Abebe, (ed.). In Proceedings of the 1stAmhara Region Regional Workshop on Potato Research and Development Achievements and Transfer Experiences and Future Directions. Bahir Dar, Ethiopia, pp. 85-101.

[7] Johnson, H. W., Robinson, H. F. and Comstock, R. E. 1955. Estimates of genetic and environmental variability in soybeans. Agronomy Journal, 47 (7): 314-318.

[8] Robinson, H. F., Comstock, R. E. and Harvey, V. H. 1949. Estimates of heritability and degree of dominance in corn. Agron. J., 41: 353-359.

[9] Rahman, M. H., 2015. Character association and genetic diversity of potato (Solanum tuberosum L.). Department of genetics and plant breeding Sher-E-Bangla Agricultural University Dhaka -1207, (MSc. Thesis), Bangladesh.

[10] Ethiopian National Metrological Agency of Bahir Dar Branch. 2018.

[11] Adet Agricultural Research Center. 2018. Fertilizer recommendations for potato production in West Gojam Amhara Region, Ethiopia.

[12] Firman, D. M. and Allen, E. J. 1989. Relationship between light interception, ground cover and leaf area index in potatoes. The Journal of Agricultural Science, 113 (03), pp. 355-359.

[13] William, M. A. and G. W. Woodbury. 1968. Specific gravity dry matter relationship and reducing sugar changes affected by potato variety, production area and storage. American Journal of Potato Research, 45 (4): 119-131.

[14] Kleinkopf, G. E., Westermann, D. T., Wille, M. J. and Kleinschmidt, G. D. 1987. Specific gravity of Russet Burbank potatoes. American potato journal, 64 (11), pp. 579-587. 
[15] Talburt, W. F., Smith, O. 1959. Potato Processing; Ed. Westport C. T. The Avi Publishing.

[16] Pardo, J. E., Alvarruiz, A., Perez, J. I., Gomez, R. and Varon, R. 2000. Physical-chemical and sensory quality evaluation of potato varieties (Solanum tuberosum L.). Journal of Food Quality, 23 (2), pp. 149-160.

[17] Heinfinings, J. W. 1987. Late blight of potato (Phytophthora infestans) Technical information. Lima, Peru, Bulletin 4, 22 pp.

[18] Singh, R. K. and Chaudhury, B. D. 1985. Biometrical methods in Quantitative Genetic Analysis. Kalayoni Published, New Delhi, 318 pp.

[19] Burton, W. G. and De vane, E. H. 1953. Estimation of heritability in Tall Festuca (Fesuca arundinacea) from replicated clonal material. Agronomy Journal, (45): 478-481.

[20] Sivasubramanian, S. and Menon, N. 1973. Heterosis and inbreeding depression in rice. Madras Agricultural Journal, (60): 1139-1144.

[21] Allard, R. W. 1960. Principles of Plant Breeding. John Wiley and Sons Inc, New York, p. 485.

[22] Falconer, D. S. and Mackay, F. C. 1996. Introduction to Quantitative Genetics and environmental variability in Soya bean. Agronomy Journal, (47): 314-318.

[23] Singh B. D. 2001. Plant Breeding: Principles and Methods 6th ed. Kalyani Publishers, New Delhi, India.

[24] Addisu Fekadu, Yohannes Petros and Habtamu Zelleke. 2013. Genetic variability and association between agronomic characters in some potato (Solanum tuberosum L.) genotypes in SNNPRS, Ethiopia. International Journal of Biodiversity and Conservation 5 (8): 523-528.

[25] Getachew Asefa, Wassu Mohammed and Tesfaye Abebe. 2016. Genetic variability studies in potato (Solanum tuberosum L.) genotypes in Bale highlands, South Eastern Ethiopia. Journal of Biology, Agriculture and Healthcare, 6 (3): $117-119$.

[26] Ebrahim S., Wasu, M. and Tesfaye, A. 2018. Genetic Variability in Potato (Solanum tuberosum L. Genotypes for Tuber Quality, Yield and Yield Related Traits at Holetta, Central Highlands of Ethiopia. (MSc. Thesis, Haramaya University).

[27] Hajam, M. A., Bhat, T. A., Rather, A. M., Khan, S. H., Reyaz, L., Shah, M. A. and Paul, S. 2018. Genetic variability, heritability and genetic advance for various qualitative characters of potato. IJCS, 6 (6), pp. 518-522.

[28] Mishra, S., Singh, J. and Sharma, P. K., 2017. Studies on Parameters of Genetic Variability for Yield and its Attributing Traits in Potato (Solanum tuberosum L.). Biosciences Biotechnology Research Asia, 14 (1), pp. 489-495.

[29] Mohammed, W., 2014. Genetic variability in potato (Solanum tuberosum L.) genotypes for late blight [Phytophthora infestans (Mont.) de Bary] resistance and yield at Haramaya, Eastern Ethiopia. East African Journal of Sciences, 8 (1), pp. 13-28.

[30] Panigrahi, K. K., Pradhan, J., Panigrahi, P. and Sarkar, K. K., 2017. Genetic Variability, Character Association and Path Coefficient Analysis of Yield Attributes for Medium and Late Maturing Potato Cultivars. International Journal of Current Microbiology and Applied Sciences, 6 (7), pp. 2558-2566. 